\title{
Simultaneous acquisition of three NMR spectra in a single experiment for rapid resonance assignments in metabolomics
}

\author{
SHIVANAND M PUDAKALAKATTI ${ }^{\mathrm{a}, \mathrm{b}}$, ABHINAV DUBEY $^{\mathrm{a}, \mathrm{c}}$ and HANUDATTA S ATREYA ${ }^{\mathrm{a}, \mathrm{b} *}$ \\ ${ }^{a}$ NMR Research Centre ${ }^{b}$ Solid State and Structural Chemistry Unit ${ }^{c}$ IISc Mathematics Initiative, \\ Indian Institute of Science, Bangalore 560 012, India \\ e-mail: hsatreya@sif.iisc.ernet.in
}

MS received 14 November 2014; revised 22 February 2015; accepted 22 February 2015

\begin{abstract}
NMR-based approach to metabolomics typically involves the collection of two-dimensional (2D) heteronuclear correlation spectra for identification and assignment of metabolites. In case of spectral overlap, a 3D spectrum becomes necessary, which is hampered by slow data acquisition for achieving sufficient resolution. We describe here a method to simultaneously acquire three spectra (one 3D and two 2D) in a single data set, which is based on a combination of different fast data acquisition techniques such as G-matrix Fourier transform (GFT) NMR spectroscopy, parallel data acquisition and non-uniform sampling. The following spectra are acquired simultaneously: (1) ${ }^{13} \mathrm{C}$ multiplicity edited GFT $(3,2) \mathrm{D}$ HSQC-TOCSY, (2) $2 \mathrm{D}\left[{ }^{1} \mathrm{H}^{-1} \mathrm{H}\right]$ TOCSY and (3) $2 \mathrm{D}\left[{ }^{13} \mathrm{C}-{ }^{1} \mathrm{H}\right]$ HETCOR. The spectra are obtained at high resolution and provide high-dimensional spectral information for resolving ambiguities. While the GFT spectrum has been shown previously to provide good resolution, the editing of spin systems based on their $\mathrm{CH}$ multiplicities further resolves the ambiguities for resonance assignments. The experiment is demonstrated on a mixture of 21 metabolites commonly observed in metabolomics. The spectra were acquired at natural abundance of ${ }^{13} \mathrm{C}$. This is the first application of a combination of three fast NMR methods for small molecules and opens up new avenues for high-throughput approaches for NMR-based metabolomics.
\end{abstract}

Keywords. Metabolomics; Fast NMR spectroscopy; multiple NMR Receiver; chemical shift editing; non-uniform sampling.

\section{Introduction}

Metabolomics is becoming an important tool for disease diagnosis and drug toxicity in public health and medicine. ${ }^{1,2}$ It involves the utility of different analytical tools such as liquid chromatography (LC)-mass spectrometry (LC-MS), gas chromatography (GC)-Mass spectrometry (GC-MS) and NMR spectroscopy. ${ }^{3-5}$ NMR has a unique feature in terms of quantification and non-invasiveness. ${ }^{6,7}$ However, it is limited in terms of sensitivity and speed. While recent developments in technology such as microprobes, cryogenically cooled probes and high magnetic field strengths have addressed the problems of sensitivity, the speed of data acquisition remains a bottleneck.

An important step in the analysis of the NMR spectrum of a mixture of metabolites is the identification and resonance assignment of the individual molecules. Due to overlap of peaks in the ${ }^{1} \mathrm{H} 1 \mathrm{D}$ spectrum, this is typically accomplished using a set of homonuclear and heteronuclear 2D NMR spectra,

*For correspondence which includes two-dimensional $(2 \mathrm{D})\left[{ }^{13} \mathrm{C},{ }^{1} \mathrm{H}\right] \mathrm{HSQC}$, $2 \mathrm{D}{ }^{1} \mathrm{H}-{ }^{1} \mathrm{H}$ TOCSY and $2 \mathrm{D}\left[{ }^{13} \mathrm{C},{ }^{1} \mathrm{H}\right]$ HSQC-TOCSY. ${ }^{6,7}$ In some cases, to reduce spectral overlap, a $3 \mathrm{D}{ }^{13} \mathrm{C}$ edited HSQC-TOCSY experiment is used, which helps in providing improved resolution by spreading the peaks in the third dimension. However, due to its high minimal measurement time required for data acquisition, a 3D NMR spectrum is not always practically feasible for resonance assignment of small molecules, especially for those which are not enriched with ${ }^{13} \mathrm{C}$. This is because the conventional mode of sampling of multi-dimensional NMR spectra is a timeconsuming process. Typically, two-dimensional (2D) experiments take minutes to hours to acquire, whereas 3D experiments, which can take up to a few days, are not generally used in metabolomics. Notwithstanding this fact, only a few attempts have been made to reduce the acquisition time of high-dimensional NMR spectra for metabolomics. ${ }^{8}$ The different fast NMR methods and their combinations developed during the past decade for proteins and nucleic acids such as single-scan NMR spectroscopy (ultrafast NMR), ${ }^{9-13}$ HADMARD encoding, ${ }^{14}$ reduced dimensional (RD) 
$\mathrm{NMR}^{15-19}$ and G-matrix Fourier transform (GFT) NMR,${ }^{20-24}$ parallel receivers, ${ }^{25,26}$ covariance NMR, ${ }^{27,28}$ non-uniform sampling, ${ }^{29-31}$ rapid pulsing (reducing inter scan delay $)^{32-34}$ and spectral aliasing ${ }^{35}$ have not been satisfactorily explored in metabolomics, where their potential will provide the greatest impact.

We recently showed that the combination of two fast NMR Methods, GFT NMR and the dual receiver system, reduces measurement time of 3D NMR experiments by an order of magnitude and provides complementary information for resonance assignment. ${ }^{36}$ However, assignment remains difficult if the spectra are crowded with cross peaks overlapping within a certain range of carbon and proton chemical shifts (typically $0.4 \mathrm{ppm}$ for ${ }^{13} \mathrm{C}$ and $0.04 \mathrm{ppm}$ for ${ }^{1} \mathrm{H}$ ). Unlike in the case of proteins, the $\mathrm{CH}, \mathrm{CH}_{2}$ and $\mathrm{CH}_{3}$ groups in metabolites overlap in the similar chemical shift ranges. This is shown in figure 1, which depicts the simulated $2 \mathrm{D}$ $\left[{ }^{13} \mathrm{C},{ }^{1} \mathrm{H}\right]$ HSQC spectrum of 315 metabolites consisting of 902 peaks reported to be present in the blood serum. The chemical shift values were taken from Biological Magnetic Resonance Bank (BMRB). ${ }^{37}$ About $30 \%$ of carbon-proton correlation peaks of $\mathrm{CH}, \mathrm{CH}_{2}$, $\mathrm{CH}_{3}$ moieties (shown in different colours) have overlapping carbon chemical shifts within $\pm 0.2 \mathrm{ppm}$ of ${ }^{13} \mathrm{C}$. While $\mathrm{CH}$ and $\mathrm{CH}_{3}$ moieties are resolved to a large extent, the $\mathrm{CH}_{2}$ moieties have overlapping shifts with $\mathrm{CH}$ and $\mathrm{CH}_{3}$. This leads to challenge in assignment of resonances. To simplify the resonance assignment, we have introduced ${ }^{13} \mathrm{C}$ multiplicity editing in the dual receiver experiments, which provides high resolution and separates peaks belonging to $\mathrm{CH}, \mathrm{CH}_{2}$ and $\mathrm{CH}_{3}$ moieties.

Combined further with non-uniform sampling, the time required for acquiring the spectra is reduced by more than an order of magnitude compared with the conventional approach. This is demonstrated

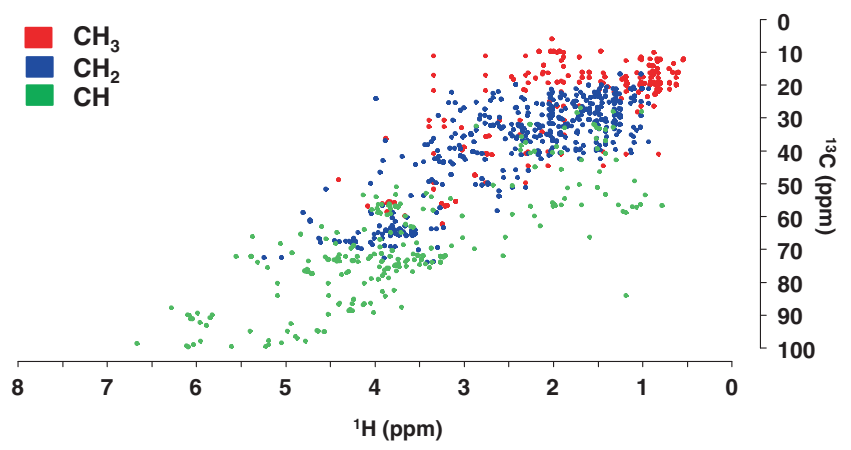

Figure 1. Simulated $2 \mathrm{D}\left[{ }^{13} \mathrm{C}-{ }^{1} \mathrm{H}\right]$ HSQC spectrum of 315 metabolites present in the blood serum. Cross peaks of $\mathrm{CH}, \mathrm{CH}_{2}, \mathrm{CH}_{3}$ moieties are depicted in different colours as indicated. for a mixture containing 21 of the commonly observed metabolites in the concentration range of $1 \mathrm{mM}$.

\section{Experimental}

\subsection{Implementation of the experiments}

The proposed experiments are implemented in a manner such that three FIDs from the three different experiments are acquired simultaneously. The primary source of magnetization is ${ }^{1} \mathrm{H}$, which is bound to ${ }^{12} \mathrm{C}(99 \%)$ and ${ }^{13} \mathrm{C}(1 \%)$. The magnetization of ${ }^{1} \mathrm{H}$ attached to ${ }^{13} \mathrm{C}$ and ${ }^{12} \mathrm{C}$ are channelled through different pathways. This is depicted figuratively in figure 2 and is similar to the experiments demonstrated previously for the non-multiplicity version. ${ }^{36}$ In brief, proton magnetization is first brought to a transverse plane. The ${ }^{1} \mathrm{H}$ spins attached to ${ }^{13} \mathrm{C}$ transfer part of their magnetization to ${ }^{13} \mathrm{C}$ via INEPT (Insensitive Nuclei Enhancement by Polarization Transfer) and the remaining magnetization is retained on itself. This is achieved by tuning the INEPT delay to $1 / 4 * \mathrm{~J}_{\mathrm{CH}} \cdot{ }^{36}$ The magnetization on ${ }^{13} \mathrm{C}$ originating from ${ }^{1} \mathrm{H}$ is frequency labelled during $\left(t_{1}\right)$ for joint sampling with ${ }^{1} \mathrm{H}\left(t_{1}\right)$ using a scaling factor $(\kappa)$. After the chemical shift evolution period of ${ }^{13} \mathrm{C}$, the multiplicity editing block: $\tau_{1}-180_{\mathrm{x}}^{0}\left({ }^{1} \mathrm{H}\right), 180_{\mathrm{x}}^{0}\left({ }^{13} \mathrm{C}\right)$ $\tau_{1}$ is inserted to differentiate $\mathrm{CH}, \mathrm{CH}_{2}, \mathrm{CH}_{3}$. The ${ }^{13} \mathrm{C}$ magnetization is transferred back to ${ }^{1} \mathrm{H}$ and the signal is detected in proton channel. This results in the GFT spectrum. The magnetization of ${ }^{1} \mathrm{H}$ attached to ${ }^{13} \mathrm{C}$, which was retained is transferred to ${ }^{13} \mathrm{C}$ via J-coupling and the signal is detected in carbon channel to get $2 \mathrm{D}$ $\left[{ }^{13} \mathrm{C},{ }^{1} \mathrm{H}\right]$ HETCOR. The chemical shift of proton $\left({ }^{1} \mathrm{H}\right)$ attached to ${ }^{12} \mathrm{C}$ evolves during $t_{1}$ in a semi-constant time manner, and preserved as it is throughout the pulse sequence and isotropically mixed and finally signal is detected in proton channel with decoupling from ${ }^{13} \mathrm{C}$, resulting in the $2 \mathrm{D}\left[{ }^{1} \mathrm{H},{ }^{1} \mathrm{H}\right]$ TOCSY spectrum. We denote the three spectra as: DR-GFT multiplicity edited $(3,2) \mathrm{D}\left[{ }^{13} \mathrm{C},{ }^{1} \mathrm{H}\right]$ HSQC-TOCSY, DR- $\left({ }^{13} \mathrm{C},{ }^{1} \mathrm{H}\right)$ HETCOR, and DR $\left({ }^{1} \mathrm{H},{ }^{1} \mathrm{H}\right)$ TOCSY (figure 3 ). The prefix DR denotes 'dual receiver'. ${ }^{36}$

The radiofrequency (r.f.) pulse scheme is shown in figure 3. The acquisition of DR-GFT multiplicity edited $(3,2)$ D HSQC-TOCSY is accomplished by joint increment of ${ }^{13} \mathrm{C}$ chemical shift along with ${ }^{1} \mathrm{H}$ in a quadrature detection using the States method by varying $\varphi_{\mathrm{a}}=x$, $y$. Thus, the four FIDs collected by independently varying $\varphi_{\mathrm{a}}$ and $\varphi_{\mathrm{b}}$. The obtained FIDs are pre-processed by multiplying with G-matrix to generate linearly combined ${ }^{1} \mathrm{H}_{\mathrm{i}}$ chemical shift with its directly attached ${ }^{13} \mathrm{C}_{\mathrm{i}}$ along $\omega_{1}$ axis and ${ }^{1} \mathrm{H}_{\mathrm{i}}$ TOCSY correlation along $\omega_{2}$ 


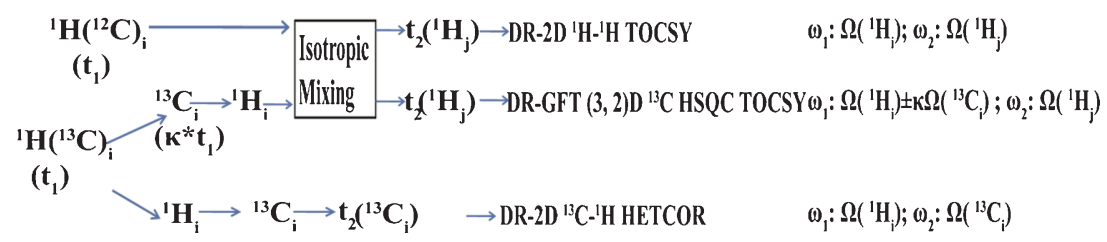

Figure 2. The magnetization transfer pathway implemented in the dual receiver experiments.

axis. The FIDs of 2D TOCSY and DR-GFT multiplicity edited $(3,2)$ D HSQC-TOCSY are collected simultaneously. Separation of the two FIDs is accomplished by acquiring 2D TOCSY and DR-GFT multiplicity edited $(3,2)$ D HSQC-TOCSY in an interleaved manner with same and opposite phases in consecutive transients, respectively. This is achieved by collecting the FID of DR-GFT multiplicity edited $(3,2)$ HSQC-TOCSY with phase $\varphi_{2}=\mathrm{x}$, -x (figure 3). The FID from the two scans are added/subtracted for separating the two FIDs of 2D TOCSY and DR-GFT multiplicity edited $(3,2)$ D HSQC-TOCSY. Note that the additional scans used above for interleaving the data sets come from the scans used for signal averaging and thus contribute to the increase in signal to noise. Thus, no additional time is invested for collecting the two data sets. The $2 \mathrm{D}\left[{ }^{13} \mathrm{C}\right.$, $\left.{ }^{1} \mathrm{H}\right]$ HETCOR is acquired and stored in separate data set.

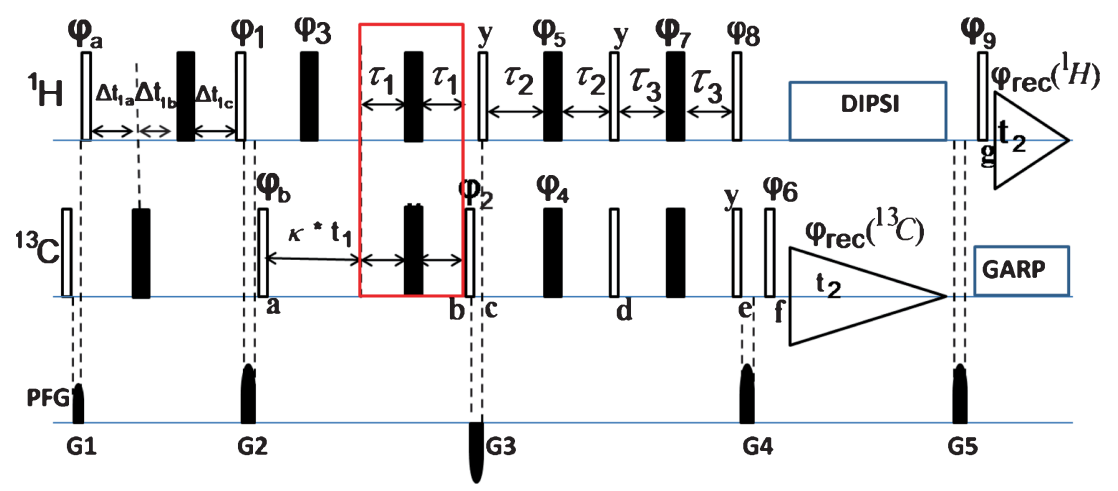

Figure 3. The r.f. pulse sequence of DR-GFT ${ }^{13} \mathrm{C}$ multiplicity edited $(3,2) \mathrm{D}$ HSQC-TOCSY, DR- $\left[{ }^{13} \mathrm{C},{ }^{1} \mathrm{H}\right]$ HETCOR and DR- $\left[{ }^{1} \mathrm{H},{ }^{1} \mathrm{H}\right]$ TOCSY is depicted. The empty thin and filled thick vertical bars represent hard $90^{\circ}$ and $180^{\circ}$ r.f. pulses respectively. All pulses are indicted with phases, if they are not applied along $x$ axis. High power hard $90^{\circ}{ }^{1} \mathrm{H}$ pulse length is $9 \mu \mathrm{s}$ and $12 \mu \mathrm{s}$ for high power hard $90^{\circ}{ }^{13} \mathrm{C}$ r.f. pulse in the solution state. The ${ }^{13} \mathrm{C}$ r.f. carrier is placed at $40 \mathrm{ppm}$ and the ${ }^{1} \mathrm{H}$ carrier position is set to $4.7 \mathrm{ppm}$ throughout the duration of the experiment. Chemical shift evolution of ${ }^{1} \mathrm{H}$ during $t_{1}$ is carried out in a semi-constant time manner. The initial values $\left(t_{1}=0\right)$ of $t_{1 \mathrm{a}}(0), t_{1 \mathrm{~b}}(0)$ and $t_{1 \mathrm{c}}(0)$ are $0.9 \mathrm{~ms}, 3 \mu \mathrm{s}$ and $0.9 \mathrm{~ms}$, respectively $\left(1 /\left(8{ }^{1} \mathrm{~J}_{\mathrm{HC}}\right) ;{ }^{1} \mathrm{~J}_{\mathrm{HC}}=140 \mathrm{~Hz}\right)$ such that $\mathrm{T}=1.8 \mathrm{~ms}$. For semi-constant time evolution, the values of $\Delta t_{1 \mathrm{~b}}$ and $\Delta t_{1 \mathrm{c}}$ are based on the number of increments and the spectral width. For 512 complex points and spectral width of $20,000 \mathrm{~Hz}(25 \mathrm{ppm})$ used for the indirect $\left({ }^{1} \mathrm{H}\right)$ dimension in the current study, the values of $\Delta t_{1 \mathrm{a}}, \Delta t_{1 \mathrm{~b}}$ and $\Delta t_{1 \mathrm{c}}$ are 25 , 23.3 and $-1.7 \mu \mathrm{s}$. The chemical shift evolution period of ${ }^{13} \mathrm{C}$ during $t_{1}$ is coincremented with that of ${ }^{1} \mathrm{H}$ with a relative scaling factor $(\kappa)$. The delays used are $\tau_{1}=3.6 \mathrm{~ms}, \tau_{2}=1.79 \mathrm{~ms}, \tau_{3}=893 \mu \mathrm{s}$ and GARP is employed to decouple ${ }^{13} \mathrm{C}$ from ${ }^{1} \mathrm{H}$. A ${ }^{13} \mathrm{C}$ spectral width of $200 \mathrm{ppm}$ is chosen for the direct dimension (in 2D HETCOR) and $25 \mathrm{ppm}$ for the indirect dimension (in DRGFT multiplicity edited (3,2)D HSQC TOCSY and 2D ${ }^{1} \mathrm{H}-{ }^{1} \mathrm{H}$ TOCSY). A mixing time of $80 \mathrm{~ms}$ is use for isotropic mixing of ${ }^{1} \mathrm{H}$ with DIPSI. The delays are $\tau_{1}=1.8 \mathrm{~ms}, \tau_{2}=0.9 \mathrm{~ms}$. Phase cycling: $\varphi_{1}=\mathrm{y},-\mathrm{y} ; \varphi_{2}=\mathrm{x},-\mathrm{x} ; \varphi_{3}=\mathrm{x}$, $\mathrm{x},-\mathrm{x},-\mathrm{x} ; \varphi_{4}=\mathrm{x}, \mathrm{x},-\mathrm{x},-\mathrm{x} ; \varphi_{5}=\mathrm{x},-\mathrm{x} ; \varphi_{6}=\mathrm{x}, \mathrm{x},-\mathrm{x},-\mathrm{x} ; \varphi_{7}=\mathrm{x}, \mathrm{x},-\mathrm{x},-\mathrm{x} ; \varphi_{8}=$ $\mathrm{x},-\mathrm{x} ; \varphi_{9}=\mathrm{x}, \mathrm{x},-\mathrm{x},-\mathrm{x} ; \varphi_{\text {(rec) }}\left({ }^{13} \mathrm{C}\right)=\mathrm{x}, \mathrm{x},-\mathrm{x},-\mathrm{x} ; \varphi_{(\mathrm{rec})}\left({ }^{1} \mathrm{H}\right)=\mathrm{x},-\mathrm{x},-\mathrm{x}, \mathrm{x}$. The PFGs applied have Sinc shaped with strengths: $\mathrm{G} 1=19 \mathrm{G} / \mathrm{cm} ; \mathrm{G} 2=19 \mathrm{G} / \mathrm{cm}$; $\mathrm{G} 3=-19 \mathrm{G} / \mathrm{cm} ; \mathrm{G} 4=19 \mathrm{G} / \mathrm{cm} ; \mathrm{G} 5=11 \mathrm{G} / \mathrm{cm}$; Quadrature detection in $t_{1}$ $\left({ }^{1} \mathrm{H}\right)$ out in States manner (i.e., $\left.\varphi_{\mathrm{a}}=\mathrm{x}, \mathrm{y}\right)$. The ${ }^{13} \mathrm{C}$ multiplicity edited block is highlighted in red colour rectangular box. 
Table 1. Experimental parameters used for data acquisition.

\begin{tabular}{|c|c|c|c|c|c|c|c|c|c|c|}
\hline \multirow{2}{*}{$\begin{array}{l}\text { Experiment } \\
\text { Name }\end{array}$} & \multicolumn{4}{|c|}{$\begin{array}{c}\text { Spectral width } \\
(\mathrm{ppm}) \text { and Nucleus } \\
\text { detected }\end{array}$} & \multicolumn{2}{|c|}{$\begin{array}{l}\text { Acquisition } \\
\text { time } \\
\left(\mathrm{t}_{\max }\right)(\mathrm{ms})\end{array}$} & \multicolumn{2}{|c|}{$\begin{array}{l}\text { No of } \\
\text { complex } \\
\text { points }\end{array}$} & \multirow{2}{*}{$\begin{array}{l}\text { Measurement } \\
\text { time* }\end{array}$} & \multirow{2}{*}{$\begin{array}{c}\text { Signal/ } \\
\text { Noise } \\
\text { Ratio }^{\S}\end{array}$} \\
\hline & Nuc. & $\mathrm{F} 1$ & Nuc & $\mathrm{F} 2$ & $\mathrm{~F} 1$ & $\mathrm{~F} 2$ & F1 & $\mathrm{F} 2$ & & \\
\hline $\begin{array}{l}\text { DR-GFT }{ }^{13} \mathrm{C} \text { multiplicity edited } \\
\text { GFT }(3,2) \text { D HSQC TOCSY }\end{array}$ & ${ }^{1} \mathrm{H}$ & 25 & ${ }^{1} \mathrm{H}$ & 16 & 13 & 160 & 512 & 2048 & $10.5 \mathrm{Hrs}$ & $5.0 \pm 1.7$ \\
\hline${ }^{1} \mathrm{H}-{ }^{1} \mathrm{H}$ TOCSY & ${ }^{1} \mathrm{H}$ & 25 & ${ }^{1} \mathrm{H}$ & 16 & 13 & 160 & 512 & 2048 & & $70 \pm 30$ \\
\hline $2 \mathrm{D}^{13} \mathrm{C}-{ }^{1} \mathrm{H}$ HETCOR & ${ }^{1} \mathrm{H}$ & 25 & ${ }^{13} \mathrm{C}$ & 200 & 13 & 78 & 512 & 3072 & & $5.5 \pm 2.1$ \\
\hline
\end{tabular}

*A relaxation delay of $2.0 \mathrm{~s}$ was used between scans and the number of transients collected (scans) per increment is 8 .

${ }^{\S}$ A distribution of the $\mathrm{S} / \mathrm{N}$ for different spectra is given in figure S2 of Supporting Information.

The addition of ${ }^{13} \mathrm{C}$ multiplicity edited phase to $\mathrm{CH}$, $\mathrm{CH}_{2}$ and $\mathrm{CH}_{3}$ simplify the spectral analysis. The sign and intensity of the $\mathrm{CH}_{\mathrm{n}}$ resonance depends on the delay ' $\tau_{1}$ ' in the multiplicity editing block (figure 3 ; shown boxed in red colour) and given by an expression $\cos ^{n}$ $\left(2 \pi \mathrm{J}^{*} \tau_{1}\right)$ (where $n=1,2,3$ and $\tau_{1}=1 / 2 *^{1} \mathrm{~J}_{\mathrm{CH}}, \mathrm{J}=$ $140 \mathrm{~Hz}$ ). The variation of phase and intensity with different angle is shown in figure $\mathrm{S} 1$. The resonances of $\mathrm{CH}(n=1)$ and $\mathrm{CH}_{3}(n=3)$ moieties possess same phase and opposite to that of $\mathrm{CH}_{2}$ moieties $(n=2$; due to the cosine modulation). Note that the editing of the $\mathrm{CH}, \mathrm{CH}_{2}$ and $\mathrm{CH}_{3}$ groups happens only in the GFT spectra because only ${ }^{13} \mathrm{C}\left(\mathrm{t}_{1}\right)$ is edited, which is detected in the GFT spectra. The method has been utilized for assignment of a mixture of 17 amino acid and 4 metabolites. The complete assignment of resonances is given in the Supporting Information (figure S2).

\subsection{Sample Preparation and Data Collection}

The sample was prepared by mixing from stock solution the desired amount of each metabolites in $100 \%$ ${ }^{2} \mathrm{H}_{2} \mathrm{O}$. The components of mixture are Alanine, Arginine, asparagine, Cysteine, Glucose, Glutamine, Histidine, Lactate, Lysine, Isoleucine, Leucine, Methionine, Phenylalanine, Proline, Pyruvate, Serine, Taurine, Threonine, Tryptophan, Tyrosine and Valine. All experiments were carried out at $25^{\circ} \mathrm{C}$ on a Bruker Avance spectrometer operating at $800 \mathrm{MHz}$ proton resonance frequency and equipped with cryogenically cooled probe and dual receiver system. Processing of all the spectra were done using NMRPipe ${ }^{38}$ and analysis was carried out using XEASY. ${ }^{39}$ The details of data acquisition are given in table 1 .

\section{Results and Discussion}

Among the spectra acquired in the dual receiver set of experiments, 2D HETCOR is a central spectrum and assignment begins from arbitrarily selecting a cross peak $\left(\mathrm{C}_{\mathrm{i}}, \mathrm{H}_{\mathrm{i}}\right)$ from $2 \mathrm{D}$ HETCOR. The peak ${ }^{1} \mathrm{H}_{\mathrm{j}}$ belonging to the same spin system as that of $\left(\mathrm{C}_{\mathrm{i}}, \mathrm{H}_{\mathrm{i}}\right)$ is identified along the $\omega_{2}$ axis in multiplicity edited DR-GFT multiplicity edited (3,2)D HSQC-TOCSY at $\Omega\left({ }^{1} \mathrm{H}_{\mathrm{i}}\right) \pm$ $\kappa * \Omega\left({ }^{13} \mathrm{C}_{\mathrm{i}}\right)$ along $\omega_{1}$. The phase (positive or negative) of the peak provides the multiplicity of $\left(\mathrm{C}_{\mathrm{i}}, \mathrm{H}_{\mathrm{i}}\right)(\mathrm{CH}$, $\mathrm{CH}_{2}$ and $\mathrm{CH}_{3}$ ). This aids in grouping all peaks belonging to one spin system. For instance, if two metabolites have similar ${ }^{13} \mathrm{C}$ chemical shifts, their spin systems will overlap. However, if they belong to different multiplicities, all TOCSY peaks for that spin system will have the same phase. The spin system thus identified is again validated by $2 \mathrm{D}\left[{ }^{1} \mathrm{H},{ }^{1} \mathrm{H}\right]$ TOCSY and the resonance peak $\left(\mathrm{C}_{\mathrm{i}}, \mathrm{H}_{\mathrm{i}}\right)$ is assigned on 2D HETCOR. The process is repeated until all the resonances of the spin system are assigned.

The four spectra obtained for 17 amino acid and 4 metabolite mixtures are shown in figure 4 . These metabolites comprise the innovative sequential media (ISM-1) used for in vitro fertilization. ${ }^{36}$ The two DRGFT multiplicity edited $(3,2) \mathrm{D}$ HSQC-TOCSY spectra edited by ${ }^{13} \mathrm{C}$ multiplicity lead to phase discrimination between $\mathrm{CH}, \mathrm{CH}_{2}$ and $\mathrm{CH}_{3}$. All three spectra were acquired at ${ }^{13} \mathrm{C}$ natural abundance. The number of peaks observed in 2D HETCOR is $92 \%$ (61 peaks) of expected number of correlations and $\sim 90 \%$ in ${ }^{13} \mathrm{C}$ multiplicity edited DR-GFT multiplicity edited $(3,2) \mathrm{D}$ HSQC-TOCSY. The ${ }^{1} \mathrm{H}$ and ${ }^{13} \mathrm{C}$ chemical shifts of all the metabolites obtained by assigning the three spectra mapped on the 2D HETCOR spectrum is shown in figure $\mathrm{S} 3$ and their values are provided in table $\mathrm{S} 1$. The cross peaks of $\mathrm{CH}$ and $\mathrm{CH}_{3}$ appear with the same phase and opposite to that of $\mathrm{CH}_{2}$ moieties.

The transfer of magnetization is similar to the previous set of experiments and the sensitivity of the spectra is of a similar order. ${ }^{36}$ However, the peaks from $\mathrm{CH}, \mathrm{CH}_{2}$ and $\mathrm{CH}_{3}$ were not distinguishable in the earlier experiments. The multiplicity edited GFT spectrum helps to resolve peaks in the following way. Two spins 


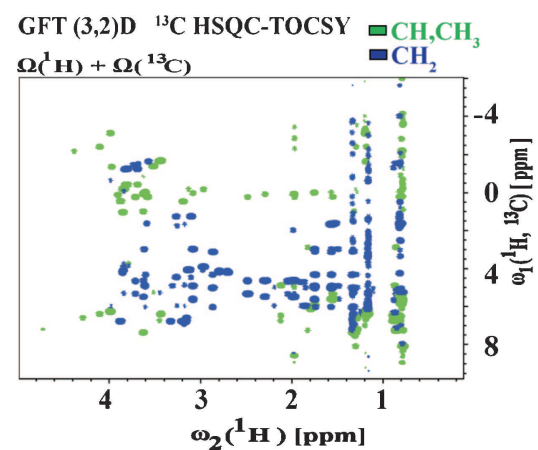

c)

DR edited HETCOR

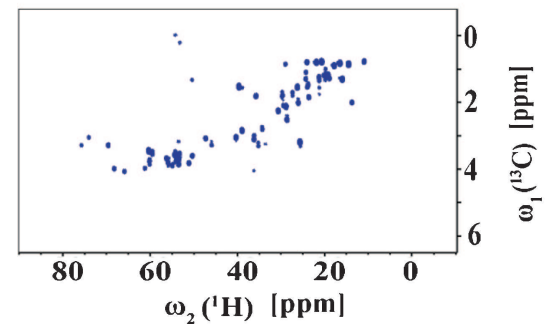

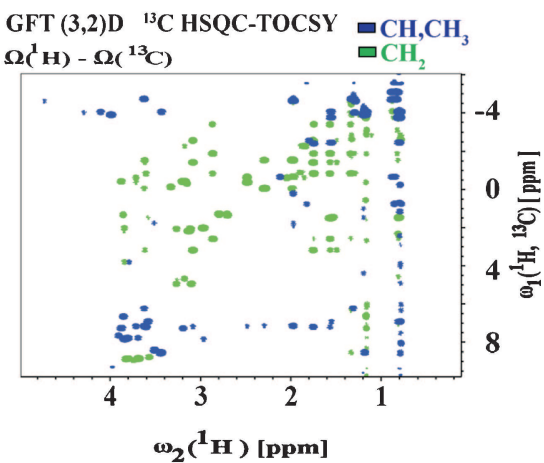

d)

DR edited TOCSY

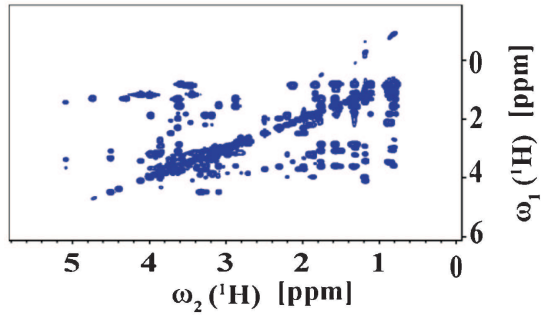

Figure 4. The ${ }^{13} \mathrm{C}$ multiplicity edited GFT $(3,2) \mathrm{D}$ HSQC-TOCSY, $2 \mathrm{D}\left[{ }^{13} \mathrm{C}\right.$, $\left.{ }^{1} \mathrm{H}\right]$ HETCOR, 2D $\left[{ }^{1} \mathrm{H},{ }^{1} \mathrm{H}\right]$ TOCSY spectra of the 21 metabolite mixture used in the current study. Note that the editing of the $\mathrm{CH}, \mathrm{CH}_{2}$ and $\mathrm{CH}_{3}$ groups happens only in the GFT spectra because only ${ }^{13} \mathrm{C}\left(\mathrm{t}_{1}\right)$ is edited during the $\tau_{1}$ delay period, which is detected in the GFT spectra.

systems that have degenerate ${ }^{13} \mathrm{C}$ shifts but different ${ }^{1} \mathrm{H}$ shifts of their attached protons are resolved in the GFT experiment due to the detection of the linear combination: $\Omega\left({ }^{1} \mathrm{H}_{\mathrm{i}}\right) \pm \kappa^{*} \Omega\left({ }^{13} \mathrm{C}_{\mathrm{i}}\right) .{ }^{36}$ However, there can be a situation when two spin systems have degenerate $\Omega\left({ }^{1} \mathrm{H}_{\mathrm{i} 0}\right) \pm \kappa^{*} \Omega\left({ }^{13} \mathrm{C}_{\mathrm{i}}\right)$ even in the GFT spectrum such that the peaks corresponding to these spin systems overlap in $\omega_{1}$ dimension. However, if they belong to different $\mathrm{CH}$ multiplicities, the peaks corresponding to one spin system can be resolved from the other system based on the phase (sign) of the peaks. This is exemplified in figure 5 for two spin systems: (Valine and Arginine) in the present study.

We carried out simulations to assess the overall impact of such resolution in general. For these simulations the 902 chemical shifts from 315 metabolites present in the blood sample (alluded to above) were used. An analysis reveals that $\sim 80 \%$ of all ${ }^{13} \mathrm{C}$ shifts

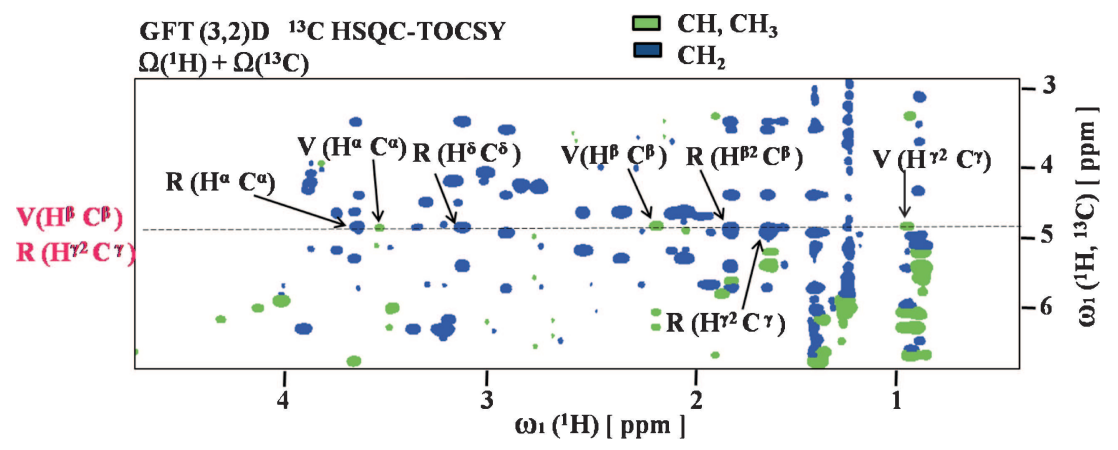

Figure 5. The chemical shift correlation of ${ }^{\prime} \mathrm{H}^{\beta} / \mathrm{C}^{\beta}$, peak of valine and ${ }^{\prime} \mathrm{H}^{\gamma} / \mathrm{C}^{\gamma}$ ' peak of arginine overlapping along $\omega_{1}$-axis of DR-GFT ${ }^{13} \mathrm{C}$ multiplicity edited $(3,2)$ D HSQC-TOCSY sub-spectrum $\left(\left[\Omega\left({ }^{1} \mathrm{H}\right)+\Omega\left({ }^{13} \mathrm{C}\right)\right]\right)$. The phase discrimination (Valine $\mathrm{H}^{\beta} / \mathrm{C}^{\beta}$ is a $\mathrm{CH}$-system and Arginine $\mathrm{H}^{\gamma} / \mathrm{C}^{\gamma}$ is $\mathrm{CH}_{2-}$ system) helps in identifying the peaks belonging to valine (green) and arginine (blue) spin systems. 
observed in the $2 \mathrm{D}\left[{ }^{13} \mathrm{C},{ }^{1} \mathrm{H}\right]$ correlation spectrum overlap (in the $\omega_{1}\left({ }^{13} \mathrm{C}\right)$ dimension) within $\pm 0.2 \mathrm{ppm}$ with ${ }^{13} \mathrm{C}$ shifts of one or more cross peaks. However, when the chemical shifts of both ${ }^{1} \mathrm{H}$ and ${ }^{13} \mathrm{C}$ are combined in the GFT experiment ${ }^{36}$ as shown in figures 2 and 4 , this overlap is reduced to $\sim 40 \%$. When one further considers the discrimination of $\mathrm{CH}, \mathrm{CH}_{2}$ and $\mathrm{CH}_{3}$ as shown above the percentage ambiguity reduces to $\sim 25 \%$. Thus, the phase discrimination of $\mathrm{CH}_{2}$ from $\mathrm{CH}$ and $\mathrm{CH}_{3}$ in DR-GFT ${ }^{13} \mathrm{C}$ multiplicity edited (3, 2)D HSQC-TOCSY helps in speeding up resonance assignments.

Data collection can be further speeded up by adopting non-uniform sampling. ${ }^{30,31,35,40-45}$ This is exemplified in figure 6, which shows the construction of the ${ }^{13} \mathrm{C}$ multiplicity edited GFT $(3,2) \mathrm{D}$ spectrum at $50 \%$ of deletion of the points (chosen with Poisson gap sampling ${ }^{31}$ ) in the indirect dimension. The spectra with $50 \%$ NUS was acquired with half the measurement time as $100 \%$. Considering the same measurement time the average SNR per unit measurement time of DR GFT $(3,2) \mathrm{D}{ }^{13} \mathrm{C}$ edited HSQC-TOCSY is $\sim 5.0$ (provided in table 1 ) and $50 \%$ NUS is $\sim 5.1$. Thus, very high-resolution spectra can be acquired within a short
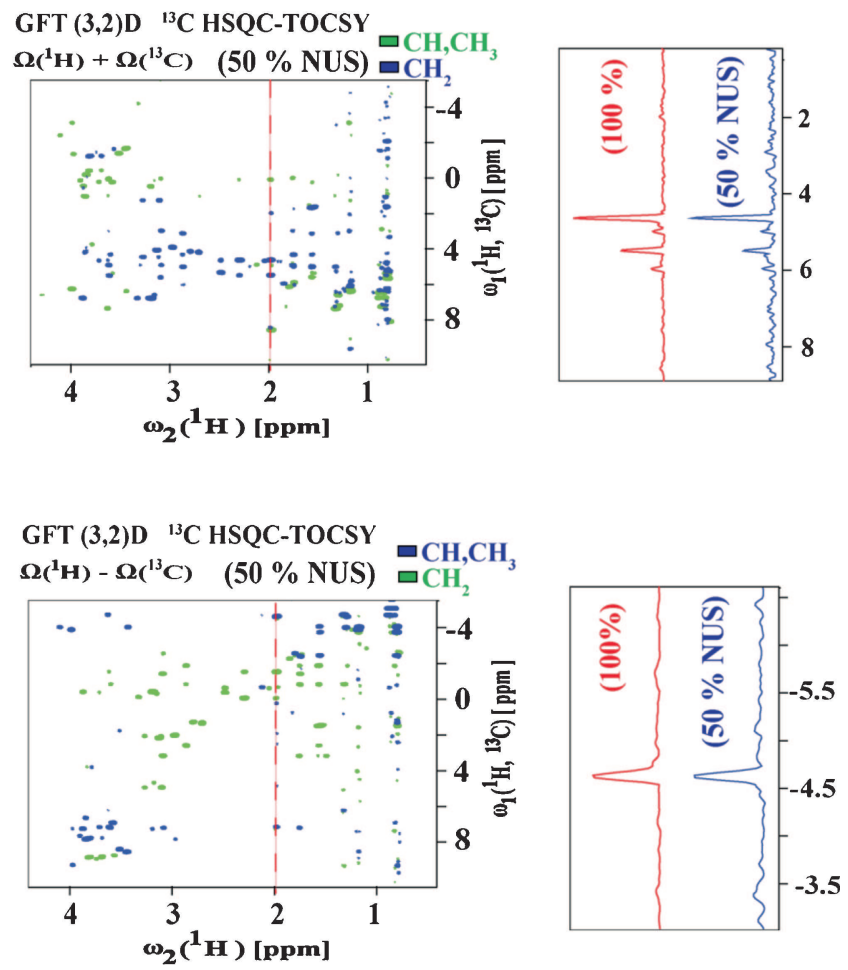

Figure 6. The DR-GFT multiplicity edited $(3,2) \mathrm{D}{ }^{13} \mathrm{C}$ HSQC-TOCSY spectra of 21 metabolite mixture are reconstructed from $50 \%$ NUS are shown in the figure. The reconstruction of spectra is done using compress sensing. The traces of 50\% NUS spectra and $100 \%$ sampled (uniformly sampled) spectra are shown on the right side of the figure. period of time using the NUS, which will be helpful for resolving near degenerate spin systems such as those of Glucose and Maltose. ${ }^{46}$ NUS will thus allow one to acquire high-resolution spectra without compromising on the measurement time.

\section{Conclusions}

In summary, we have demonstrated a new NMR-based approach applicable to metabolomics, which involves the simultaneous acquisition of three spectra in a single data set. The method is based on a combination of different fast data acquisition techniques such as G-matrix Fourier transform (GFT) NMR spectroscopy, the dual receiver system and non-uniform sampling. The spectra are obtained at high resolution and provide highdimensional spectral information for resolving ambiguities. The addition of multiplicity editing further resolves the ambiguities between the $\mathrm{CH}, \mathrm{CH}_{2}$ and $\mathrm{CH}_{3}$ groups. This opens up new avenues for high-throughput approaches for NMR-based metabolomics.

\section{Supplementary Information}

Figure S1, chemical shift assignments of metabolites mapped on to the 2D HETCOR spectrum and Table S1, list of chemical shift assignments of the metabolites obtained using the dual receiver experiments are available at www.ias.ac.in/chemsci.

\section{Acknowledgements}

The facilities provided by NMR Research Centre supported by Department of Science and Technology (DST), India, is gratefully acknowledged. HSA acknowledges support from DST (Grant no: No. IR/ S0/LU-007/20110/1) and DAE-BRNS research grants.

\section{References}

1. Beckonert O, Keun H C, Ebbels T M, Bundy J, Holmes E, Lindon J C and Nicholson J K 2007 Nat. Protoc. 2 2692

2. Lindon J C, Nicholson J K, Holmes E and Everett J R 2000 Concept. Magnetic. Res. 12289

3. Zheng C, Zhang S, Ragg S, Raftery D and Vitek O 2011 Bioinformatics 271637

4. Lanza I R, Zhang S, Ward L E, Karakelides H, Raftery D and Nair K S 2010 PloS One 5 e10538

5. Roux A, Lison D, Junot C and Heilier J -F 2011 Clinic. Biochem. 44119

6. Gowda G N, Shanaiah N and Raftery D 2012 In Isotope Labeling in Biomolecular NMR (Location:Springer) p. 147 
7. Smolinska A, Blanchet L, Buydens L M C and Wijmenga S S 2012 Anal. Chim. Acta. 75082

8. Guennec A L, Giraudeau P and Caldarelli S 2014 Anal. Chem. 865946

9. Mishkovsky M and Frydman L 2009 An. Rev. Phys. Chem. 60429

10. Shrot Y, Shapira B and Frydman L 2004 J. Magn. Reson. 171163

11. Shapira B, Karton A, Aronzon D and Frydman L 2004 J. Am. Chem. Soc. 1261262

12. Shrot Y and Frydman L 2003 J. Am. Chem. Soc. 125 11385

13. Frydman L, Lupulescu A and Scherf T 2003 J. Am. Chem. Soc. 1259204

14. Kupce E, Nishida T and Freeman R 2003 Prog. Nucl. Magn. Reson. Spectr. 4295

15. Szyperski T, Wider G, Bushweller J H and Wüthrich K 1993 J. Am. Chem. Soc. 1159307

16. Mishkovsky M, Kupce E and Frydman L 2007 J. Chem. Phys. 127

17. Freeman R and Kupce E 2006 Curr. Analy. Chem. 2101

18. Hiller S, Fiorito F, Wuthrich K and Wider G 2005 Proc. Nation. Acad. Sci. USA 10210876

19. Kupce E and Freeman R 2003 J. Am. Chem. Soc. 125 13958

20. Xia Y L, Zhu G, Veeraraghavan S and Gao X L 2004 J. Biomol. NMR 29467

21. Kim S and Szyperski T 2004 J. Biomol. NMR 28117

22. Kim S and Szyperski T 2003 J. Am. Chem. Soc. 125 1385

23. Zhang Q, Atreya H S, Kamen D E, Girvin M E and Szyperski T 2008 J. Biomol. NMR 40157

24. Franks W T, Atreya H S, Szyperski T and Rienstra C M 2010 J. Biomol. NMR 48213

25. Kupče E, Freeman R and John B K 2006 J. Am. Chem. Soc. 1289606

26. Kupče E and Kay L E 2012 J. Biomol. NMR 541

27. Bruschweiler R and Zhang F L 2004 J. Chem. Phys. 120 5253

28. Snyder D A, Zhang F and Brueschweiler R 2007 J.Biomol. NMR 39165
29. Schmieder P, Stern A S, Wagner G and Hoch J C 1993 J. Biomol. NMR 3569

30. Rovnyak D, Frueh D P, Sastry M, Sun Z Y J, Stern A S, Hoch J C and Wagner G 2004 J. Magn. Reson. 17015

31. Hyberts S G, Frueh D P, Arthanari H and Wagner G 2009 J. Biomol. NMR 45283

32. Schanda P, Kupce E and Brutscher B 2005 J. Biomol. NMR 33199

33. Kern T, Schanda P and Brutscher B 2008 J. Magn. Reson. 190333

34. Arnero C, Schanda P, Dura M A, Ayala I, Marion D, Franzetti B, Brutscher B and Boisbouvier J $2009 \mathrm{~J}$. Am. Chem. Soc. 1313448

35. Maciejewski M W, Qui H, H Z Rujan I, Mobli M and Hoch J C 2009 J. Magn. Reson. 19988

36. Pudakalakatti S M, Dubey A, Jaipuria G, Shubhashree U, Adiga S, Moskau D and Atreya H S 2014 J. Biomol. NMR 58165

37. Ulrich E L, Akutsu H, Doreleijers J F, Harano Y, Ioannidis Y E, Lin J, Livny M, Mading S, Maziuk D, Miller Z, Nakatani E, Schulte C F, Tolmie D E, Kent Wenger R, Yao H and Markley J L 2008 Nucl. Acid. Resear. 36 D402

38. Delaglio F, Grzesiek S, Vuister G W, Zhu G, Pfeifer J and Bax A J 1995 Biomol. NMR 6277

39. Bartels C, Xia T H, Billeter M, Güntert P and Wüthrich K 1995 J. Biomol. NMR 61

40. Hoch J C, Stern A S, Donoho D L and Johnstone I M 1990 J. Magn. Reson. 86236

41. Sanders C R and Prestegard J H $1991 \mathrm{~J}$. Am. Chem. Soc. 1131987

42. Hoch J C and Stern A S 1996 In NMR Data Processing 1st edition (New York: Wiley-Liss)

43. Hoch J C and Stern A S 2001 Nucl. Magn. Reson. Bio. Macromol. Part A 338159

44. Orekhov V Y, Ibraghimov I M and Billeter M 2003 J. Biomol. NMR 27165

45. Tugarinov V, Kay L E, Ibraghimov I and Orekhov V Y 2005 J. Am. Chem. Soc. 1272767

46. Pudakalakatti S M, Chandra K, Thirupathi R and Atreya H S 2014 Chem. Eur. J. 2015719 